\title{
Tolerância do cultivar de milheto ADR-300 ao herbicida atrazine ${ }^{1}$
}

\author{
Tolerance of pearl millet cultivar ADR-300 to atrazine herbicide
}

\author{
Hugo de Almeida Dan ${ }^{2 *}$, Alberto Leão de Lemos Barroso ${ }^{3}$, Tiago Rezende Finotti ${ }^{4}$, Lilian Gomes de Moraes \\ Dan $^{5}$ e Renato Lara de Assis 6
}

\begin{abstract}
Resumo - Este trabalho teve por objetivo avaliar a seletividade do herbicida atrazine para a cultura do milheto (Pennisetum glaucum). O ensaio foi implantado em vasos com capacidade de $10 \mathrm{dm}^{-3} \mathrm{de}$ solo, em condições de casa de vegetação em delineamento inteiramente casualizado, por meio do esquema fatorial 5 x 3 com quatro repetições, correspondendo a cinco doses de atrazine: $0 ; 0,5 ; 1,5 ; 2,5$ e 4,0 $\mathrm{kg} \mathrm{ha}^{-1}$, aplicadas em três estádios de crescimento do milheto (duas, quatro e oito folhas expandidas) cultivar ADR-300. Foram avaliados os níveis de fitotoxicidade aos 7 e 21 dias após a aplicação, altura das plantas, biomassa seca da parte aérea e massa das espigas. Maiores sintomas de fitointoxicação seguido de redução no acúmulo de biomassa seca foram obtidos em aplicações realizadas nos estádios mais precoces da cultura e se intensificaram com o incremento da dose do herbicida. Em relação à massa da espiga, doses inferiores a $1,5 \mathrm{~kg} \mathrm{ha}^{-1}$ de atrazine apresentaram maior flexibilidade quanto ao estádio de aplicação, podendo ser utilizadas de forma segura visando o manejo de plantas daninhas no cultivar ADR-300.
\end{abstract}

Palavras-chave - Gramínea. Triazinas. Seletividade.

\begin{abstract}
The aim of this study was evaluate the selectivity of the herbicide atrazine to the culture of pearl millet (Pennisetum glaucum). The test was implemented in units of $10 \mathrm{dm}^{-3}$ of soil under conditions of a greenhouse in a completely randomized design in factorial scheme $5 \times 3$ with four replicates, corresponding to five dose of atrazine: 0 ; $0.5 ; 1.5 ; 2.5$ and $\left(4.0 \mathrm{~kg}\right.$ i.a. ha ${ }^{-1}$ ), applied in three stages of growth of pearl millet (two, four and eight expanded leave), cultivar ADR-300. We evaluated the levels of phytotoxicity at 7; 14 and 21 days after application, plant height, dry mass and mass of spike. The major symptoms of phytotoxicity, reducing the number of tillers and dry biomass were obtained from applications made in the early stages of culture and intensified with increasing dose of atrazine. With respect to the mass of spike, doses below $1.5 \mathrm{~kg} \mathrm{ha}^{-1}$ of atrazine showed greater flexibility in the application stage and can be used safely view the management of weeds in ADR-300.
\end{abstract}

Key words - Grass. Triazines. Selectivity.

\footnotetext{
* Autor para correspondência

'Recebido para publicação em 25/08/2009; aprovado em 07/02/2011

Parte do trabalho de Iniciação Científica do terceiro autor desenvolvido com bolsa PIBIC

${ }^{2}$ Programa de Pós-Graduação em Agronomia/UEM, Maringá-PR, Brasil, 87.020-900, halmeidadan@gmail.com

${ }^{3}$ Departamento de Agronomia/FESURV, Rio Verde-GO, Brasil, all_barroso@hotmail.com

${ }^{4}$ Graduação em Agronomia/FESURV, Rio Verde-GO, Brasil, tfinotti@yahoo.com.br

${ }^{5}$ Programa de Pós-Graduação em Agronomia/UEM, Maringá-PR, Brasil, lilian-agronoma@hotmail.com

${ }^{6}$ Instituto Federal Goiano Campus Iporá, Rodovia GO 060, Km 01 Iporá-GO, Brasil, 76.200-000
} 


\section{Introdução}

Devido a sua grande adaptação em diferentes biomas, o milheto vem ganhando destaque nos últimos anos (BERTIN et al., 2005; DAN et al., 2010; DANTAS et al., 2006; MURAISHI et al., 2005; SUZUKI et al., 2006), principalmente com a chegada de híbridos de alto potencial produtivo, oriundos do melhoramento genético. Isso fez com que essa planta deixasse de ser uma simples espécie de cobertura ou produção de palha para o plantio direto, passando a ser considerada uma cultura de valor econômico para produção de grãos e forragem, tornado-se difundida no cerrado brasileiro (DAN et al., 2009).

Apesar da rusticidade, apresenta crescimento inicial lento tornando-se vulnerável a interferência causada pela mato-competição. Nesse contexto as plantas daninhas podem ser um fator limitante para o desenvolvimento da cultura. Segundo Carson (1987), o não-controle das plantas daninhas durante o período crítico de competição, que vai até sete semanas após a emergência das plantas, pode reduzir a produtividade de grãos em até $36 \%$. Para Berglund (1998), o controle de plantas daninhas nessa cultura deve ser realizado bem cedo, pois as plantas de milheto só toleram a presença de plantas daninhas ao atingirem de 15 a $20 \mathrm{~cm}$ de altura.

Como na maioria das espécies cultivadas, o controle químico é uma ferramenta imprescindível para o manejo integrado de plantas daninhas em regiões onde predominam grandes extensões de cultivo. Apesar de ser uma espécie que vem ganhado destaque na região dos cerrados, segundo Pereira Filho et al. (2003), não existem no mercado brasileiro, herbicidas registrados para cultura do milheto. Além disso, a disponibilidade de herbicidas seletivos é limitada. Mesmo assim, o controle de espécies latifoliadas tem se mostrado seguro com utilização dos herbicidas 2,4 D (FARINELLI et al., 2005; PACHECO et al., 2007; SHAW; ARNOLD, 2002) e carfentrazona (LYON et al., 2007).

Atualmente, um dos herbicidas que tem ganhado destaque na cultura do milheto é o atrazine. Possui mecanismo de ação que inibe o fotossistema II e que apresenta boa seletividade tanto na pré quanto na pósemergência das culturas do milho e sorgo (SILVA; SILVA, 2007), podendo ser usado tanto de forma isolada (FORNAROLLI et al., 1999; MACIEL et al., 2002), quanto em associações com outros herbicidas, como mesotrione (TIMOSSI, 2009) e nicosulfuron (LÓPEZOVEJERO et al., 2003; RIZZARDI et al., 2008) para o controle de plantas daninhas na cultura do milho.

Embora o atrazine seja usado como alternativa de herbicida para o controle de plantas daninhas latifoliadas nas culturas do milho e sorgo, são escassas as informações referentes à sua seletividade para o milheto. Dowler e Wright (1995) verificaram baixa tolerância do milheto ao atrazine, propachlor e pendimethalin, quando usados isoladamente e em misturas na pré-emergencia da cultura. Ndhai et al. (1980), avaliando a seletividade de vários herbicidas do grupo das triazinas, verificaram que o milheto mostrou-se tolerante ao herbicida atrazine quando aplicado em pós-emergência na metade da dose recomendada para a cultura do milho; no entanto, Magalhães et al. (2000) verificaram que ocorreu redução na biomassa após a utilização do atrazine na cultura do sorgo.

Nesse contexto, este trabalho teve por objetivo avaliar a seletividade do herbicida atrazine aplicado em pós-emergência da cultura do milheto.

\section{Material e métodos}

O experimento foi conduzido em casa de vegetação no Campus da Faculdade de Agronomia da FESURV-Universidade de Rio Verde, em Rio Verde, GO, localizada nas coordenadas $17^{\circ} 48^{\prime}$ S e $55^{\circ} 55^{\prime}$ $\mathrm{W}$, e altitude de $760 \mathrm{~m}$, durante o período de maio a novembro de 2008. O clima da região é caracterizado como úmido tropical, com duas estações bem definidas: seca no inverno e úmida no verão.

As unidades experimentais foram compostas de vasos de $10 \mathrm{dm}^{3}$ de capacidade, preenchidos com Latossolo Vermelho distroférrico, de textura argilosa, coletado na camada de 20 a $40 \mathrm{~cm}$ de profundidade. As características químicas e físicas da amostra do solo foram: $\mathrm{pH}$ em água: 4,$4 ; \mathrm{Ca}: 1,36 \mathrm{cmol}_{\mathrm{c}} \mathrm{dm}^{-3} ; \mathrm{Mg}: 0,73 \mathrm{cmol}_{\mathrm{c}} \mathrm{dm}^{-3}$; Al: $0,45 \mathrm{cmol}_{\mathrm{c}} \mathrm{dm}^{-3} ; \mathrm{H}+\mathrm{Al}: 4,8 \mathrm{cmol}_{\mathrm{c}} \mathrm{dm}^{-3} ; \mathrm{K}: 65 \mathrm{mg}$

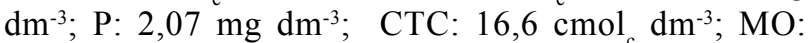
$21,67 \mathrm{~g} \mathrm{~kg}^{-1}$, Argila $600 \mathrm{~g} \mathrm{~kg}^{-1}$, Silte $50 \mathrm{~g} \mathrm{~kg}^{-1}$ e Areia $350 \mathrm{~g} \mathrm{~kg}^{-1}$, segundo a Embrapa (1997).

A correção da acidez do solo foi realizada 30 dias antes da semeadura do milheto, utilizando-se o equivalente a 1,78 toneladas de calcário dolomítico (PRNT 98\%) por hectare. No momento da semeadura, realizou-se uma adubação de base com $60 \mathrm{~kg} \mathrm{ha}^{-1}$ de $\mathrm{P}_{2} \mathrm{O}_{5}$ (super fosfato simples), $20 \mathrm{~kg} \mathrm{ha}^{-1}$ de $\mathrm{K}_{2} \mathrm{O}$ (cloreto de potássio) e $20 \mathrm{~kg} \mathrm{ha}^{-1}$ de nitrogênio (sulfato de amônia).

$\mathrm{O}$ ensaio foi conduzido em delineamento inteiramente casualisado com quatro repetições, em esquema fatorial 5 × 3 correspondendo a cinco doses de atrazine (Atrazina Nortox $500 \mathrm{SC}^{\circledR}$ ) nas doses de 0; 0,5; 1,5; 2,5 e 4,0 kg de i.a. ha-1 aplicados em três estádios fenológicos da planta daninha: Estádio 1 (plântulas com duas folhas expandidas, 15 dias após a emergência); Estádio 2 (plantas com quatro folhas expandidas, cerca de 21 dias após a emergência); Estádio 3 (plantas com oito 
folhas expandidas, de um a dois perfilhos, cerca de 28 dias após a emergência). Em todos os tratamentos herbicidas foi adicionada a calda $0,5 \% \mathrm{v} / \mathrm{v}$ do óleo mineral Attach.

A semeadura do milheto cv. ADR-300 ocorreu a $1,5 \mathrm{~cm}$ de profundidade, sendo que logo após a emergência, as plântulas foram desbastadas, para que fossem mantidas duas plântulas por unidade experimental.

A aplicação dos tratamentos herbicidas foi realizado com pulverizador costal com pressurização por $\mathrm{CO}_{2}$, munido de quatro pontas de pulverização do tipo TT 110-02 (barra de $2 \mathrm{~m}, 0,5 \mathrm{~m}$ entre pontas), utilizando um volume de calda equivalente a $100 \mathrm{~L} \mathrm{ha}^{-1}$. As condições ambientais no momento das aplicações eram as seguintes: Estádio 1 (Temperatura, média de $22,2{ }^{\circ} \mathrm{C}$, UR de $85 \%$ e velocidade do vento de $3,0 \mathrm{~km} \mathrm{~h}^{-1}$ ); Estádio 2 (Temperatura, média de $26,1^{\circ} \mathrm{C}$, UR de $77 \%$ e velocidade do vento de 3,5 $\mathrm{km} \mathrm{h}^{-1}$ ); Estádio 3 (Temperatura, média de $29,7{ }^{\circ} \mathrm{C}$, UR de $89 \%$ e velocidade do vento de $5,1 \mathrm{~km} \mathrm{~h}^{-1}$ ). Todas as aplicações foram iniciadas no mesmo horário, 8:4, justamente devido às melhores condições para aplicação. A irrigação foi retomada 24 horas após a aplicação dos tratamentos, com o intuito de evitar perdas do herbicida por lavagem foliar.

As avaliações de fitointoxicação foram realizadas aos 7 e 21 dias após a aplicação dos tratamentos (DAA), utilizando-se escala percentual de 0 (zero) a $100 \%$, onde 0 (zero) representa ausência de sintomas e 100\% representa a morte de todas as plantas. Foram determinadas também a altura das plantas (medida com uma régua do colo da planta à extremidade final da última folha) aos 50 dias após a emergência. Aos 60 dias após a emergência foi determinado o número de perfilhos por planta e no final da fase reprodutiva obteve-se a massa seca da parte aérea e o peso das espigas (sem o pedúnculo). A biomassa verde passou pelo processo de secagem em estufa com circulação de ar a $65^{\circ} \mathrm{C}$ durante um período de 72 horas.

Os resultados referentes aos níveis de fitointoxicação foram submetidos a uma transformação $(\sqrt{ } \mathrm{x}+1)$ para seguir os pressupostos necessários para a análise de variância, que foi realizada com o programa estatístico Sisvar. Foram ajustados modelos lineares de regressão para as variáveisresposta que apresentam significância, utilizando-se posteriormente o programa Sigma Plot versão 10.0 para a confecção das curvas de regressão.

\section{Resultados e discussão}

Houve interação significativa entre as doses de atrazine e os estádios de desenvolvimento do milheto cv. ADR 300 (TAB. 1), em relação a todas as variáveis analisadas, indicando que dependendo da dose ou estádio pelo qual foi realizado a aplicação, o atrazine pode apresentar diferentes níveis de seletividade com relação ao cultivar.

Observa-se inicialmente, aos sete dias após a aplicação (DAA), que os níveis de fitointoxicação máximos apresentados pela cultura foram de $66 ; 27$ e 22\%, respectivamente, para aplicações realizadas no estádio 1; 2 e 3, mostrando que os maiores níveis de injúria foram obtidos em aplicações mais precoces (FIG. 1A).

Durante a avaliação de 21 DAA, as plantas de milheto apresentaram injúrias em menor intensidade, indicando a intensa capacidade de recuperação da espécie, no entanto os valores de fitointoxicação seguiram a mesma tendência, isto é, aplicações realizadas em estádios mais precoces de desenvolvimento apresentaram maiores taxas de crescimento de fitointoxicação (FIG. 1B). Comportamento semelhante foi obtido por Grichar et al. (2005) para cultura do sorgo granífero.

Tabela 1 - Resumo da análise de variância, com os quadrados médios, e significância dos modelos para as variáveis: fitointoxicação aos 7 e 21 (DAA), altura de planta (AL), Massa seca da parte aérea (AE) e massa das espiga (MP) de milheto em função do estádio e doses de atrazine

\begin{tabular}{ccccrrr}
\hline \multirow{2}{*}{ F.V. } & \multirow{2}{*}{ G.L. } & \multicolumn{2}{c}{ Fitointoxicação } & \multirow{2}{*}{ AL } & Massa seca & Massa da espiga \\
\cline { 3 - 4 } & & \multicolumn{1}{c}{ 7DAA } & 21DAA & & & \\
\hline Herbicida & 4 & $876,54^{*}$ & $2440,65^{*}$ & $1296,93^{*}$ & $112,40^{*}$ & $267,85^{*}$ \\
Estádio & 2 & $102,06^{*}$ & $1228,21^{*}$ & $715,41^{*}$ & $19,10^{*}$ & $31,67^{*}$ \\
H x E & 8 & $14,40^{*}$ & $258,11^{*}$ & $8,95^{*}$ & $6,73^{*}$ & $8,55^{*}$ \\
Resíduo & 45 & 1,18 & 6,24 & 5,61 & 4,01 & 5,81 \\
\hline Média & & 7,05 & 13,89 & 89,18 & 70,94 & 57,79 \\
CV\% & & 13,32 & 19,32 & 7,48 & 5,64 & 10,03 \\
\hline
\end{tabular}

* significativo a $5 \%$ e não significativo pelo teste $\mathrm{F}$ 


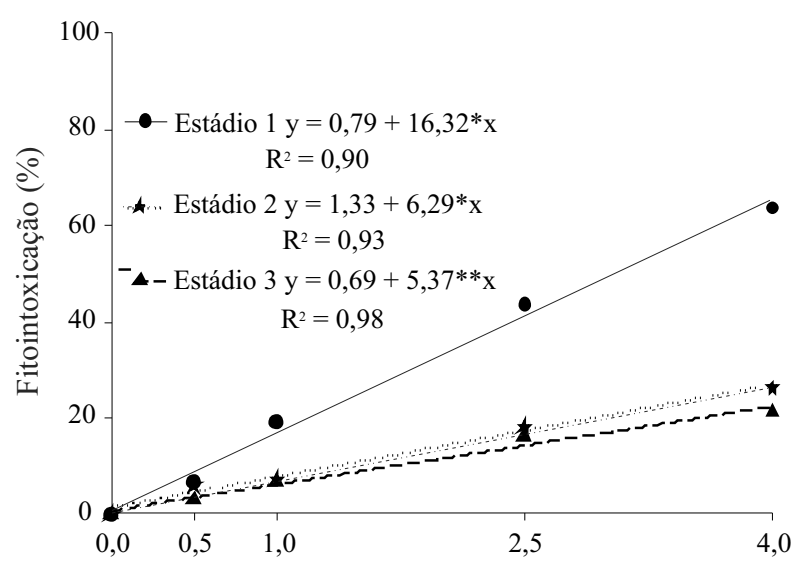

(A)

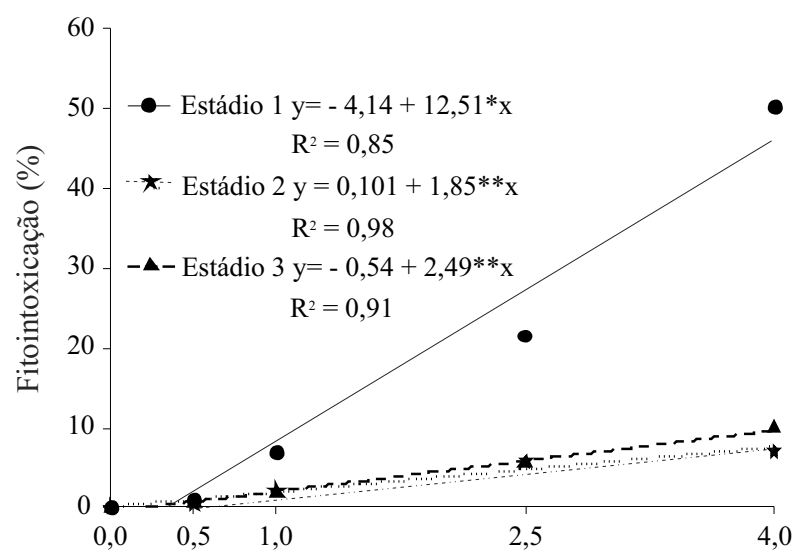

(B)

Dose de atrazine $\left(\mathrm{kg} \mathrm{ha}^{-1}\right)$

Figura 1 - Fitointoxicação apresentada pelas plantas de milheto em função das doses de atrazine aos 7 (A) e 21 (B) dias após a aplicação (DAA) para diferentes estádios de aplicação do herbicida

Embora em todos os casos a porcentagem de fitointoxicação seja diretamente relacionada à dose aplicada de atrazine, plantas que receberam o herbicida no estádio 1 apresentaram incrementos sobre a porcentagem de fitointoxicação numa taxa aproximadamente três vezes maior do que aqueles que receberam a aplicação no estádio 3, evidenciando a maior sensibilidade da espécie em aplicações muito precoces (FIG. 1B).

Durante o período de avaliação, os sintomas mais evidentes apresentados pelas plantas de milheto foram: clorose internervural seguida de necrose nas bordas das folhas, o que segundo Weller (2003), estes são sintomas característicos dos herbicidas pertencentes aos inibidores do fotossistema II. Em plantas mais sensíveis essa sintomatologia pode ser expressiva logo aos quatro dias após a aplicação.

Apesar da injúria apresentar-se em função da dose e do estádio utilizado para a aplicação, o cultivar ADR-300 apresentou grande tolerância ao atrazine, principalmente nos estádios mais avançados de desenvolvimento. Semelhantes resultados foram observados por LópezOvejero et al. (2003) para a cultura do milho. Segundo Silva e Silva (2007) umas das explicações plausíveis para esse aumento na tolerância em gramíneas relaciona-se à menor absorção através dos tecidos foliares ou mesmo à existência de compostos como benzoxazinonas capazes de proporcionar reações como hidroxilação, dealquilação e até mesmo conjugação, reduzindo a atividade do herbicida. Para Marcacci et al. (2005), o citocromo P450 é o grande responsável pela dealquilação do herbicida em plantas tolerantes. Prado et al. (1995) constataram que a seletividade de atrazine ao Panicum dichotomiflorum ocorreu devido ao processo de conjugação com os compostos cisteina e glutationa.

Com relação à altura das plantas, a utilização de atrazine apresentou maior potencial supressor quando a aplicação ocorreu no estádio mais precoce do milheto (FIG. 2A). Observa se que a redução na altura da planta apresenta-se de forma diretamente proporcional à dose utilizada na aplicação. Em aplicações tardias (Estádios 2 e 3) essa variável é menos influenciada, quando comparada ao estádio 1. Entretanto, observase que doses superiores a $2,5 \mathrm{~kg} \mathrm{ha}^{-1}$ de atrazine podem proporcionar reduções superiores a $5 \%$ mesmo quando realizada em estádios mais avançados de desenvolvimento. É importante frisar que a altura das plantas é um fator primordial no processo de colheita dos grãos, já que na região dos cerrados, essa espécie é colhida mecanicamente.

Ao analisar o comportamento dos percentuais de acúmulo na biomassa seca em relação aos valores obtidos pela testemunha (FIG. 2B), constata-se que as maiores reduções foram obtidas quando a aplicação do herbicida ocorreu no estádio 1. Fato esse, pode estar relacionado à maior fitointoxicação causada pelo herbicida, onde o acréscimo de cada $\mathrm{kg}$ de herbicida proporciona um decréscimo de aproximadamente $14 \%$ na biomassa seca acumulada durante todo o ciclo de vida da planta. Para o estádio 3, essa redução foi de apenas $6 \%$. Esse pode ser um fator negativo para quem trabalha com milheto visando a produção de forragem, necessitando de maior cautela com relação à dose e estádio de utilização desse herbicida.

Uma das explicações mais plausíveis para o menor acúmulo de biomassa seca, trata-se da redução da área foliar sinteticamente ativa, já que o referido herbicida inibe ou suprime todo o aparato fotossintético localizado 


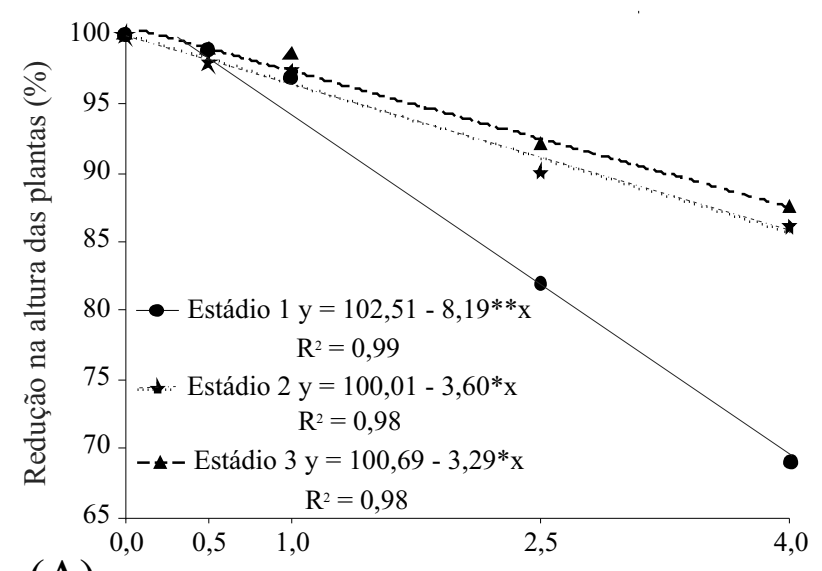

(A)

Dose de atrazine $\left(\mathrm{kg} \mathrm{ha}^{-1}\right)$

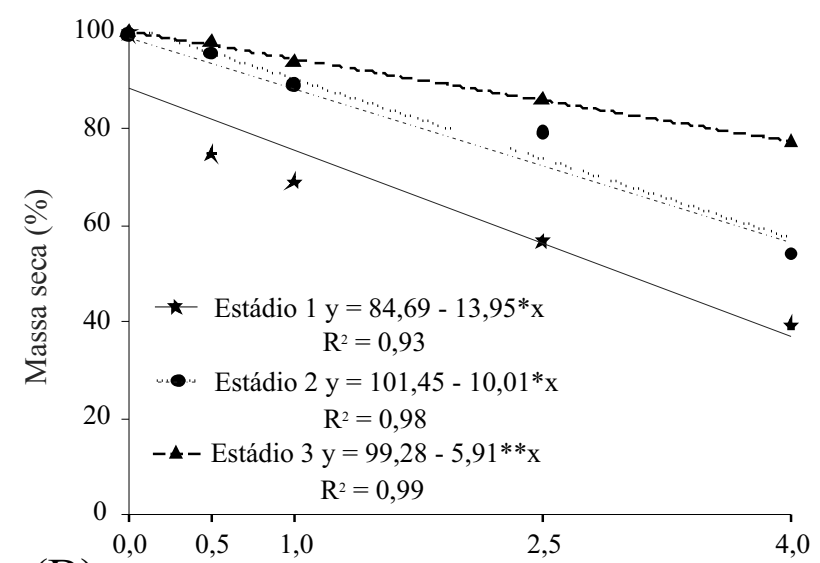

(B)

Dose de atrazine $\left(\mathrm{kg} \mathrm{ha}^{-1}\right)$

Figura 2 - Altura das plantas de milheto (A) e acúmulo de massa seca em relação a testemunha (B), em função da dose de atrazine e do estádio da planta no momento da aplicação

no fotossitema II, dificultando a transferência de elétrons (SILVA et al., 2007). Este fato repercutiu diretamente sobre a produção de fotoassimilados e consequentemente de biomassa.

Tratando-se dos aspectos relacionado ao rendimento, as plantas de milheto apresentaram reduções expressivas quando submetidas a doses crescentes de atrazine (FIG. 3). Comparando-se os coeficientes angulares dos modelos lineares ajustadas, observa-se dentro do intervalo de doses estudado, que valores máximos de redução no rendimento da cultura foram de 54; 40 e 29\%, respectivamente, para aplicações realizadas no estádio 1 ; 2 e 3 , ou seja, as reduções foram mais expressivas, nas aplicações realizadas precocemente, e se intensificam com o incremento da dose.

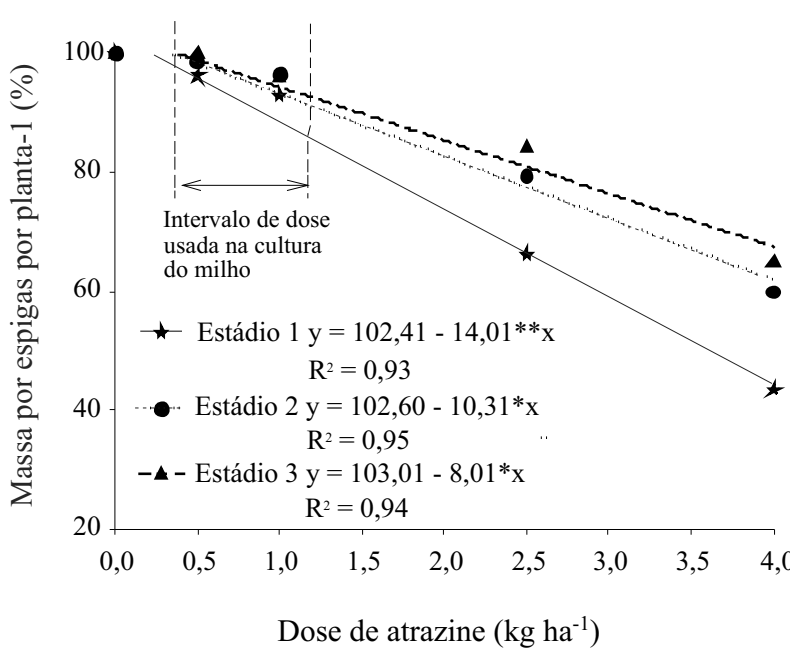

Figura 3 - Massa da espiga (\% em relação à testemunha), em função da dose e da época de aplicação de atrazine

Caso seja levado em consideração o intervalo de doses recomendado para a cultura do milho (entre 0,5 e $1,5 \mathrm{~kg} \mathrm{ha}^{-1}$ de atrazine), as equações ajustadas aos dados de massa das espigas (FIG. 3) indicam que o herbicida poderá injuriar o cultivar ADR-300 e reduzir sua produtividade, aproximadamente, entre $5 ; 3$ e $2 \%$, caso a aplicação $\left(0,5 \mathrm{~kg} \mathrm{ha}^{-1}\right)$ seja realizada nos estádios 1; 2 e 3, respectivamente. Com o incremento da dose $\left(1,5 \mathrm{~kg} \mathrm{ha}^{-1}\right)$, tais reduções seriam de 18; $12 \mathrm{e}$ $9 \%$. Sob condições normais de lavoura, esta redução de produtividade provavelmente seja menor do que as perdas qualitativas e quantitativas provocadas pela competição com plantas daninhas, justificando o uso do herbicida.

\section{Conclusão}

É possível concluir por meio do presente trabalho que doses inferiores a $1,5 \mathrm{~kg} \mathrm{ha}^{-1}$ de atrazine apresentaram maior flexibilidade quanto ao estádio de aplicação, podendo ser utilizadas de forma segura visando o manejo de plantas daninhas na cultivar de milheto ADR-300.

\section{Referências}

BERGLUND, D. R. Proso millet in North Dakota. Fargo: North Dakota State University, 1998. 7 p.

BERTIN, E. G.; ANDRIOLI, I.; CENTURION, J. F. Plantas de cobertura em pré-safra ao milho em planto direto. Acta Scientiarum, v. 27, n. 03, p. 379-386, 2005. 
CARSON, A. G. Improvement weed management in the draft animal-based production of early pearl millet in Gambia. Tropical Pest Management, v. 33, n. 02, p. 359-363, 1987.

DAN, H. A. et al. Seletividade de herbicidas aplicados na pós-emergência da cultura do milheto (Pennisetum Glaucum). Revista Brasileira de Milho e Sorgo, v. 08, n. 03, p. 297 306, 2009.

DAN, H. A. et al. Seletividade do herbicida tembotrione à cultura do milheto. Planta Daninha, v. 28, n. 04, p. 793799, 2010.

DANTAS, J. A. et al. Efeito da salinidade sobre o crescimento e composição mineral de seis clones de Pennisetum. Revista Ciência Agronômica, v. 37, n. 01, p. 97-101, 2006.

DOWLER, C. C.; WRIGHT, D. L. Weed management systems for pearl millet in the southessterm United States. In: NATIONAL GRAIN PEARL MILLETS, 1., 1995, Tifton.Proceedings... Tifton: University of Georgia, 1995. p. 64-71.

EMPRESA BRASILEIRA DE PESQUISA AGROPECUÁRIA (EMBRAPA). Centro Nacional de Pesquisa de Solos. Manual de métodos de análises de solo. 2. ed., Rio de Janeiro: EMBRAPA, 1997. 212 p.

FARINELLI, R.; PENARIOL, F. G.; LEMOS, L. B. Eficiência do herbicida 2,4-D no controle de Raphanus raphanistrum L. em pós-emergência na cultura do milheto. Revista Brasileira de Milho e Sorgo, v. 04, n. 02, p. 104-111, 2005.

FORNAROLLI, D. A. et al. Influência do horário de aplicação no comportamento de atrazine e misturas aplicadas em pósemergência na cultura do milho. Planta Daninha, v. 17, n. 01, p. 119-120, 1999.

GRICHAR, W. J.; BRENT, A.; BREWER, K. D. Weed Control and Grain Sorghum (Sorghum bicolor) response to postemergence applications of atrazine, pendimethalin, and trifluralin. Weed Technology, v. 19, n. 04, p. 999-1003, 2005.

LYON, D. J.; KNISS, A.; MILLER, S. D. Carfentrazone improves broadleaf weed control in proso and foxtail millets. Weed Technology, v. 21, n. 03, p. 84-87, 2007.

LÓPEZ-OVEJERO, R. F. et al. Seletividade de herbicidas para a cultura de milho (Zea mays) aplicados em diferentes estádios fenológicos da cultura. Planta Daninha, v. 21, n. 03, p. 413-419, 2003.

MACIEL, C. D. G. et al. Método alternativo para avaliação da absorção de atrazine por plantas de Brachiaria plantaginea. Planta Daninha, v. 20, n. 03, p. 431-438, 2002.
MARCACCI, S. et al. The possible role of hydroxylation in the detoxification of atrazine in mature vetiver (Chrysopogon zizanioides Nash) grown in hydroponics. Journal of Bioscience, v. 05 , n. 60 , p. $427-34,2005$.

MAGALHÃES, P. C. et al.,. Fitotoxicidade causada por herbicidas na fase inicial de desenvolvimento da cultura do sorgo. Planta Daninha, v. 18, n. 03, p. 483-490, 2000.

MURAISHI, C. T. et al. Manejo de espécies vegetais de cobertura de solo e produtividade do milho e da soja em semeadura direta. Acta Scientiarum, v. 27, n. 02, p. 199-207, 2005.

NDAHI, W. B.; RUSS, O. G.; MOSHIER, L. J. Growth of pearl millet (Pennisetum americanum (L.) Leeke) as influenced by selected herbicide applications and delay in planting. In: VANDERLIP, R. L. (Ed.) Improvement of pearl millet. Second annual report. Manhattan: Kansas State University, 1980. p. 67-71.

PACHECO, L. P. et al. Tolerância do milheto (Pennisetum americanum) ao 2,4-D. Planta Daninha, v. 25, n. 01, p. 173179, 2007.

PEREIRA FILHO, I. A. et al. Manejo da cultura do milheto. Sete Lagoas: EMBRAPA milho e sorgo, 2003. 17 p. (Circular Técnico, 29).

PRADO, R.; ROMERA, E.; MENENDEZ, J. Atrazine detoxification in Panicum dichotomiflorum and target site Polygonum lapathifolium. Pesticide Biochemistry and Physiology, v. 52, n. 01, p. 1-11, 1995.

SHAW, D. R.; ARNOLD, J. C. Weed control from herbicide combinations with glyphosate. Weed Technology, v. 16, n. 01, p. 1-6, 2002.

SILVA, A. A. et al. Herbicidas: classificação e mecanismo de ação. In: SILVA, A. A.; SILVA, J. F. (Ed.) Tópicos em manejo de plantas daninhas. Viçosa, MG: Universidade Federal de Viçosa, 2007. p.83-148.

TIMOSSI, P. C. Manejo de rebrotes de Digitaria insularis no plantio direto de milho. Planta Daninha, v. 27, n. 01, p. 175-179, 2009.

SUZUKI, L. E. A. S.; ALVES, M. C. Fitomassa de plantas de cobertura em diferentes sucessões de culturas e sistemas de cultivo. Bragantia, v. 65, n. 01, p. 121-127, 2006.

RIZZARDI, M. A. et al. Controle de plantas daninhas em milho em função de épocas de aplicação de nitrogênio. Planta Daninha, v. 26, n. 01, p.113-121, 2008.

WELLER, S. Herbicide action course. West Lafayette: Purdue University, 2003. 689 p. 